\title{
Zinc oxide-chitosan nanobiocomposite for urea sensor
}

\author{
Pratima R. Solanki, ${ }^{\text {a) }}$ Ajeet Kaushik, Anees A. Ansari, G. Sumana, and B. D. Malhotra ${ }^{\text {a) }}$ \\ Biomolecular Electronics \& Conducting Polymer Research Group, National Physical Laboratory, \\ Dr. K. S. Krishnan Marg, New Delhi 110012, India
}

(Received 31 July 2008; accepted 20 August 2008; published online 24 October 2008)

\begin{abstract}
Zinc oxide $(\mathrm{ZnO})$-chitosan $(\mathrm{CH})$ nanobiocomposite film onto indium-tin-oxide (ITO) coated glass has been used to immobilize urease (Urs) and glutamate dehydrogenase (GLDH) for urea detection. The presence of $\mathrm{ZnO}$ nanoparticles in $\mathrm{CH}$ results in its increased surface area and enhanced electron transfer kinetics. The Urs-GLDH/CH-ZnO/ITO bioelectrode characterized using electrochemical, Fourier transform infrared, and scanning electron microscopy studies exhibit linearity of $5-100 \mathrm{mg} / \mathrm{dl}$, detection limit of $3 \mathrm{mg} / \mathrm{dl}$, response time of $10 \mathrm{~s}$, reproducibility as 20 times, and shelf life of 3 months. The low Michaelis-Menten constant $\left(K_{m}\right)$ value $(4.92 \mathrm{mg} / \mathrm{dl})$ indicates enhanced affinity of enzyme with nanobiocomposite. () 2008 American Institute of Physics. [DOI: $10.1063 / 1.2980448]$
\end{abstract}

Estimation of urea in serum/blood/urine is important for diagnosis of renal and liver diseases. An increase in urea level (normal range is $8-20 \mathrm{mg} / \mathrm{dl}$ ) in blood and urine causes renal failure, urinary tract obstruction, dehydration, shock, burns, and gastrointestinal bleeding. Moreover, reduced urea level may cause hepatic failure, nephritic syndrome, and cachexia (low-protein and high-carbohydrate diets).

Most urea biosensors based on urease (Urs) are based on catalytic conversion of urea to hydrogen bicarbonate and ammonium. ${ }^{1-3}$ It has been observed that ammonium ions easily diffuse in solution. Thus, glutamate dehydrogenase $^{4,5}$ (GLDH) has been used as an alternate since it catalyzes the reaction between ammonium ions, $\alpha$-ketoglutarate $(\alpha-\mathrm{KG})$ and nicotinamide adenine dinucleotide (NADH) to produce L-glutamate and NAD .

The immobilization of Urs on a given matrix is a crucial step for the fabrication of urea biosensor. Extensive efforts have been made to utilize nanomaterials to immobilize Urs for urea detection. Among nanostructured metal oxides such as cerium oxide $\left(\mathrm{CeO}_{2}\right),{ }^{6}$ tin oxide $\left(\mathrm{SnO}_{2}\right)$, and zirconium oxide $\left(\mathrm{ZrO}_{2}\right)^{7}$ nanoparticles etc., zinc oxide $(\mathrm{ZnO})^{8}$ nanoparticles have been used for fabrication of transducer surface because of their unique ability to promote faster electron transfer between electrode and active site of desired enzyme. This has been attributed to their remarkable properties such as wide band gap $(3.37 \mathrm{eV})$, high surface area, high catalytic efficiency, nontoxicity, chemical stability, strong adsorption ability [high isoelectric point (IEP) 9.5], ${ }^{9}$ and for immobilization of low IEP $(\sim 5.0)$ proteins via electrostatic interactions. $\mathrm{ZnO}$ nanoparticles have recently been used for direct adsorption and interaction of desired enzymes with $\mathrm{ZnO}$ nanoparticles. The biocompatible $\mathrm{ZnO}$ nanoparticles have unique advantages for enzyme immobilization due to desirable microenvironment for enhanced direct electron transfer between enzyme's active sites and the electrode. ${ }^{10,11}$ However, biosensing properties of $\mathrm{ZnO}$ nanoparticles can be improved by incorporating these in chitosan $(\mathrm{CH})$ to prepare $\mathrm{ZnO}-\mathrm{CH}$ hybrid nanobiocomposite. ${ }^{12} \mathrm{CH}$ exhibits excellent film forming ability, nontoxicity, and biocompatibility has

\footnotetext{
a) Tel.: +91-11-45609152 FAX: +91-11-45609310. Electronic addresses: pratimasolanki@yahoo.com and bansi.malhotra@gmail.com.
}

led to growing interest for immobilization of biomolecules. Moreover, presence of amine and hydroxyl group in $\mathrm{CH}$ helps in the immobilization of desired enzyme. ${ }^{13-15}$ Recently, $\mathrm{ZnO}-\mathrm{CH}$ nanobiocomposite films have been proposed for amperometric immunosensor for human IgG. Moreover, ZnO-CH composite film can be used for application to $\mathrm{H}_{2} \mathrm{O}_{2}$, phenol and cholesterol biosensor, respectively. ${ }^{16}$ However, no attempts have been made towards application of $\mathrm{ZnO}-\mathrm{CH}$ nanobiocomposite film to urea detection.

We report results of studies relating to immobilization of Urs-GLDH onto $\mathrm{ZnO}-\mathrm{CH}$ nanobiocomposite film deposited onto indium-tin-oxide (ITO) glass substrate for fabrication of urea sensor.

$\mathrm{ZnO}$ nanoparticles $(5 \mathrm{mg}$ ) prepared using coprecipitation method ${ }^{17}$ were dispersed into $\mathrm{CH}$ solution $(50 \mathrm{mg}$ of $\mathrm{CH}$ was dissolved in $10 \mathrm{ml}$ of $0.05 \mathrm{M}$ acetate buffer) with stirring at room temperature followed by sonication for about $1 \mathrm{~h}$. The $\mathrm{ZnO}$ nanoparticles film $(200 \mathrm{~nm})$ was spin-cast onto ITO glass with speed of $3000 \mathrm{rpm}$ and allowed to dry at room temperature $\left(25^{\circ} \mathrm{C}\right)$. This $\mathrm{ZnO}-\mathrm{CH} / \mathrm{ITO}$ electrode was rinsed with phosphate buffer $(50 \mathrm{mM}, p \mathrm{H} 7.0)$ to neutralize the matrix.

The solution containing Urs $(10 \mathrm{mg} / \mathrm{ml})$ and GLDH $(1 \mathrm{mg} / \mathrm{ml})$ in $1: 1$ ratio in phosphate buffer $(50 \mathrm{mM}, \mathrm{pH} 7.0)$ was immobilized onto $\mathrm{ZnO}-\mathrm{CH} / \mathrm{ITO}$ nanobiocomposite electrode by physisorption technique via electrostatic interactions between matrix and enzyme. The Urs-GLDH/ZnO-CH/ ITO bioelectrode is kept undisturbed for about $12 \mathrm{~h}$ at $4{ }^{\circ} \mathrm{C}$. Finally, the dry bioelectrode is immersed in $50 \mathrm{mM}$ PBS $(p \mathrm{H}$ 7.0) in order to wash out any unbound enzyme from the electrode surface.

X-ray diffraction (XRD), (Rigaku) studies have been done to identify the crystal structure of $\mathrm{ZnO}$ powder. Scanning electron microscopy (SEM) (LEO-440) studies have been conducted to examine surface morphologies of $\mathrm{ZnO}$ $\mathrm{CH} / \mathrm{ITO}$ nanobiocomposite and Urs-GLDH/ZnO-CH/ITO bioelectrodes. Electrochemical analysis has been conducted on an Autolab Potentiostat/ Galvanostat (Eco Chemie, Netherlands) using a three-electrode system with ITO as working electrode $\left(0.25 \mathrm{~cm}^{-2}\right)$, platinum wire as the auxiliary electrode and $\mathrm{Ag} / \mathrm{AgCl}$ electrode as reference electrode in phos-

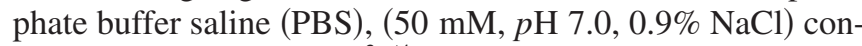
taining $5 \mathrm{mM}\left[\mathrm{Fe}(\mathrm{CN})_{6}\right]^{3-/ 4-}$. 

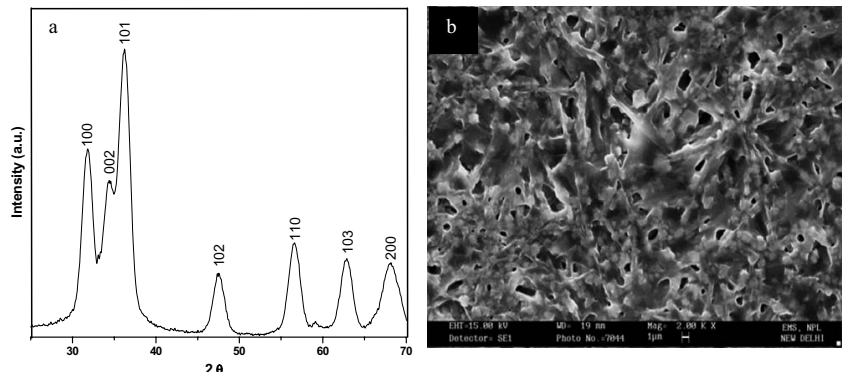

FIG. 1. (a) XRD pattern of ZnO-CH nanobiocomposite film. (b) SEM of Urs-GLDH/ZnO-CH/ITO bioelec-trode.

Figure 1(a) shows XRD pattern carried out on $\mathrm{ZnO}$ powder sample. The $\mathrm{x}$-ray diffractograms (in the range $\left.2 \theta, 30^{\circ}-70^{\circ}\right)$ of the film show presence of (100), (002), (101), (102), (110), (103), and (200) reflection planes corresponding to hexagonal wurtzite structure of $\mathrm{ZnO} .{ }^{17}$ However, broadening in reflection planes indicates nanocrystalline nature of particles. The average crystallite size of $\mathrm{ZnO}$ nanoparticles estimated according to Scherrer's formula is 4-5 nm.

Fourier transform infrared (FTIR) spectra (data not shown) of $\mathrm{ZnO}-\mathrm{CH}$ nanobiocomposite exhibits infrared bands corresponding to $\mathrm{ZnO}$ nanoparticles and pure $\mathrm{CH}$, indicating that $-\mathrm{NH}_{2}$ and $-\mathrm{OH}$ groups of $\mathrm{CH}$ due to complex formation resulting in enhanced accumulation ability of $\mathrm{ZnO}$ nanoparticles and electrocatalytic activity of $\mathrm{ZnO}-\mathrm{CH}$ nanobiocomposite film. However, shapes of the absorption peaks of $\mathrm{ZnO}-\mathrm{CH}$ nanobiocomposite become broader due to overlapping of the functional groups of Ur-GLDH and $\mathrm{ZnO}-\mathrm{CH}$ nanobiocomposite film indicating immobilization of $\mathrm{Ur}$ GLDH onto nanobiocomposite matrix.

SEM image of ZnO-CH/ITO nanobiocomposite shows cage like morphology indicating uniform dispersion of $\mathrm{ZnO}$ nanoparticles into $\mathrm{CH}$ (data not shown). SEM image of UrsGLDH/ZnO-CH [Fig. 1(b)] reveals that enzymes (UrsGLDH) are present uniformly distributed in $\mathrm{ZnO}-\mathrm{CH}$ composite. The uniform dispersion of Urs-GLDH reveals that enzyme binds with $-\mathrm{NH}_{2}$ and $-\mathrm{OH}$ terminal of $\mathrm{CH}$ via electrostatic interactions. Moreover, positively charged $\mathrm{ZnO}-\mathrm{CH}$ nanobiocomposite due to $\mathrm{CH}$ and $\mathrm{ZnO}(\mathrm{IEP} \sim 9.5)$ results in electrostatic interactions with negatively charged Urs-GLDH (IEP of 5.0-5.3 at $p \mathrm{H} \mathrm{7.0).}$

Figure 2(a) shows electrochemical impedance spectra (EIS, Nyquist plot) of $\mathrm{CH} / \mathrm{ITO}$ electrode (curve i), $\mathrm{ZnO}-\mathrm{CH} /$ ITO electrode (curve ii), and Urs-GLDH/ZnO-CH/ITO bio- electrode (curve iii). In the EIS, the semicircle diameter is equal to electron-transfer resistance $R_{\mathrm{CT}}$. The $R_{\mathrm{CT}}$ of $\mathrm{CH}$ decreases from 3.27 to $2.04 \mathrm{k} \Omega$ after incorporation of $\mathrm{ZnO}$ nanoparticles, indicating that $\mathrm{ZnO}$ nanoparticles result in enhanced electron transfer kinetics on nanobiocomposite electrode. After immobilization of Urs-GLDH onto $\mathrm{ZnO}-\mathrm{CH}$ nanobiocomposte, $R_{\mathrm{CT}}$ increases to $9.47 \mathrm{k} \Omega$ revealing immobilization of Urs-GLDH onto $\mathrm{ZnO}-\mathrm{CH} / \mathrm{ITO}$ matrix resulting in blocking of charge carriers in the nanobiocomposite. The variations of solution resistance $\left(R_{s}\right)$, double layer capacitance $\left(C_{\mathrm{dl}}\right)$, and Warburg element $\left(Z_{\mathrm{W}}\right)$ are shown in Fig. 2(a).

Figure 2(b) shows cyclic voltammograms of $\mathrm{CH} / \mathrm{ITO}$ electrode, $\mathrm{ZnO}-\mathrm{CH} / \mathrm{ITO}$ electrode, and Urs-GLDH/ZnO-CH/ ITO bioelectrode. It is observed that magnitude of peak current slightly decreases and peak potential shifts toward lower potential $\left(E_{\mathrm{pa}} \sim 0.23 \mathrm{~V}\right)$ as compared to that of $\mathrm{CH} / \mathrm{ITO}$ electrode. The decrease of peak current and shift of the oxidation peak potential of $\mathrm{ZnO}-\mathrm{CH} / \mathrm{ITO}$ electrode may be attributed to faster electron transfer in $\mathrm{ZnO}-\mathrm{CH}$ nanobiocomposite. Further, redox current of Urs-GLDH/ZnO-CH/ITO bioelectrode is found to decrease due to insulating characteristics of Urs-GLDH indicating slow down of redox process during the biochemical reaction.

Figure 2(c) shows CVs of Urs-GLDH/ZnO-CH/ITO bioelectrode as a function of scan rate from 10 to $100 \mathrm{mV} / \mathrm{s}$. The proportional increase of redox current with respect to scan rate is observed indicating diffusion-controlled system [inset Fig. 2(c)]. The surface concentration of Urs-GLDH/ $\mathrm{ZnO}-\mathrm{CH} / \mathrm{ITO}$ bioelectrode estimated from plot of Ip versus scan rate $\left(\nu^{1 / 2}\right)$ using Brown-Anson model has been found to be $3.8 \times 10^{-8} \mathrm{~mol} \mathrm{~cm}^{-2}$. The diffusion coefficient value $(D)$ of $\mathrm{ZnO}-\mathrm{CH} / \mathrm{ITO}$ electrode has been estimated using SandelSevcik equation

$$
I_{p}=\left(2.69 \times 10^{5}\right) n^{3 / 2} A D^{1 / 2} C \nu^{1 / 2},
$$

where $I_{p}$ is peak current ( $I_{\mathrm{pa}}$ anodic and $I_{\mathrm{pc}}$ cathodic), $n$ is electron stoichiometry, $A$ is electrode area $\left(0.25 \mathrm{~cm}^{2}\right), D$ is diffusion coefficient, $C$ is surface concentration (3.8 $\left.\times 10^{-8} \mathrm{~mol} \mathrm{~cm}^{-2}\right)$, and $\nu$ is scan rate $(10 \mathrm{~V} / \mathrm{s})$. The $D$ value has been obtained as $8.22 \times 10^{-4} \mathrm{~cm}^{2} \mathrm{~s}^{-1}$.

Figure 3(a) shows electrochemical response of Urs$\mathrm{GLDH} / \mathrm{ZnO}-\mathrm{CH} / \mathrm{ITO}$ bioelectrode as a function of urea in presence of NADH $(30 \mu \mathrm{l})$ and $\alpha$-ketoglutamate $(70 \mu \mathrm{l})$ studied using $C V$ technique. The magnitude of peak current increases linearly as urea concentration increases (linear range as 5-100 mg/dl). Inset (i) in Fig. 3(a) exhibits linear
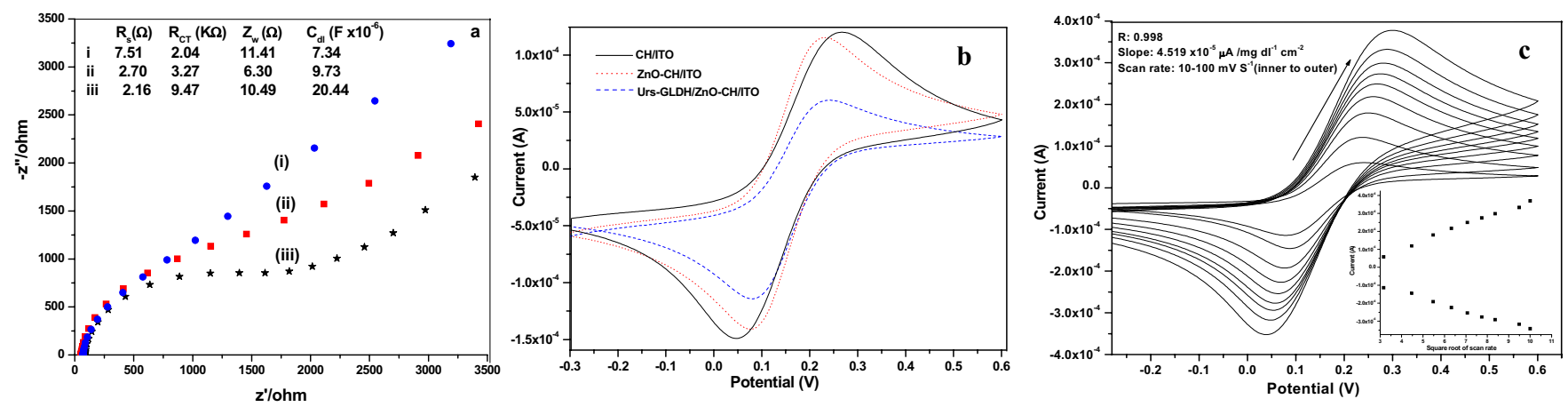

FIG. 2. (Color online) (a) EIS of (i) $\mathrm{CH} / \mathrm{ITO}$, (ii) ZnO-CH/ITO electrode, and (iii) Urs-GLDH/ZnO-CH/ITO. (b) Cyclic voltammogram of CH/ITO, $\mathrm{ZnO}-\mathrm{CH} / \mathrm{ITO}$ and Urs-GLDH/ZnO-CH/ITO bioelectrode at $10 \mathrm{mV} / \mathrm{s}$ scan rate in PBS containing $5 \mathrm{mM}\left[\mathrm{Fe}(\mathrm{CN})_{6}\right]^{3-/ 4-}$ (c) $\mathrm{CV}$ of Urs-GLDH/ZnO-CH/ITO bioelectrode at different scan rates, $10-100 \mathrm{mV} / \mathrm{s}$. 

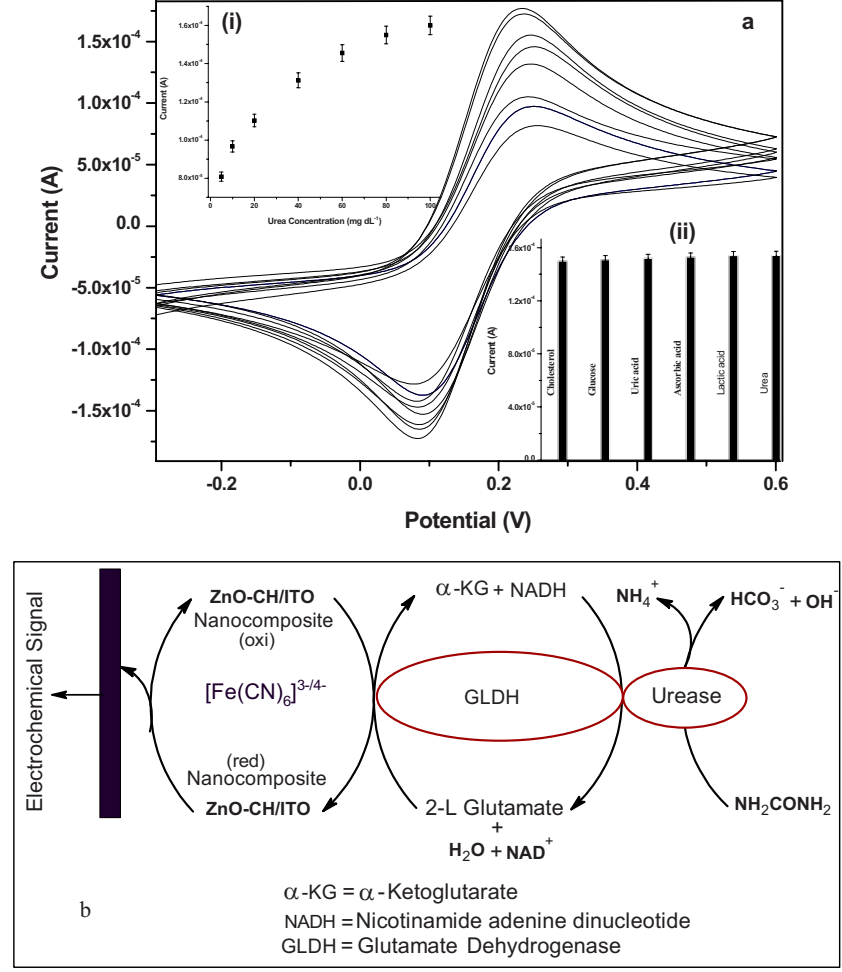

FIG. 3. (Color online) (a) Electrochemical response of Urs-GLDH/ZnO$\mathrm{CH} / \mathrm{ITO}$ bioelectrode with respect to urea concentration $\left(5-100 \mathrm{mg} \mathrm{dl}^{-1}\right)$ at scan rate of $10 \mathrm{mV} \mathrm{s}^{-1}$. Inset a: linearity curve between magnitude of current vs urea concentration. Inset b: effect of interferents on Urs-GLDH/ZnO-CH/ ITO bioelectrode. (b) The electrochemical reaction at Urs-GLDH/ZnO-CH/ ITO bioelectrode.

increase in current as a function of urea concentration. It may be noted that values of electrochemical response current obtained using several Urs-GLDH/ZnO-CH/ITO bioelectrodes are reproducible within $0.1 \%$.

Electrochemical reaction occurring at Urs-GLDH/ZnO$\mathrm{CH} / \mathrm{ITO}$ bioelectrode is shown in Fig. 3(b). The MichaelisMenten constant $\left(K_{m}\right)$ value obtained using Linweaver-Burke equation has been estimated as $4.92 \mathrm{mg} / \mathrm{dl}(0.82 \mathrm{mM})$ with sensitivity as $0.13 \mu \mathrm{A} / \mathrm{mM} \mathrm{cm}^{2}$, linear regression as 0.988 , and standard deviation as $9.4 \mu \mathrm{A} / \mathrm{mg} \mathrm{dl}^{-1}$. The lower $K_{m}$ value reflects higher enzymatic affinity of Urs-GLDH/ZnO$\mathrm{CH} / \mathrm{ITO}$ with urea due to biocompatibility, active surface area, and high electron communication capability of $\mathrm{ZnO}-\mathrm{CH}$ nanobiocomposite.

The detection limit has been estimated as $3 \mathrm{mg} / \mathrm{dl}$ using $3 \sigma_{b} / m$ criteria, where $m$ is slope of the calibration graph and $\sigma_{b}$ is standard deviation of the blank signal. The reproducibility of response of bioelectrode has been investigated at $10 \mathrm{mg} / \mathrm{dl}$ urea concentration. No significant decrease in current is observed after using at least 20 times. This bioelectrode achieves $95 \%$ of steady state current in less than $5 \mathrm{~s}$ indicating fast electron exchange between Urs-GLDH and $\mathrm{ZnO}-\mathrm{CH} / \mathrm{ITO}$ electrode.

The effect of $p \mathrm{H}\left(6.0-8.0\right.$ at $\left.25{ }^{\circ} \mathrm{C}\right)$ on Urs-GLDH/ZnO$\mathrm{CH} / \mathrm{ITO}$ bioelectrode has been studied using $C V$ to estimate enzyme activity that depends upon the conformation and electrostatic state of the enzyme's active site. The highest current (data not shown) is obtained at $p \mathrm{H} 7.0$ revealing that bioelectrode is most active at this $p \mathrm{H}$. Thus, all the experiments are carried out at a $p \mathrm{H}$ of 7.0 at $25^{\circ} \mathrm{C}$.

The selectivity of Urs-GLDH/ZnO-CH/ITO bioelectrode has been estimated by comparing magnitude of the current response by adding normal concentration of interferents such as glucose $(5 \mathrm{mM})$, ascorbic acid $(0.05 \mathrm{mM})$, uric acid $(0.1 \mathrm{mM})$, cholesterol $(5 \mathrm{mM})$, and lactic acid $(5 \mathrm{mM})$. The role of interferents has been examined by mixing desired interferent in equal concentrations with that of urea and the results are depicted in inset (ii), Fig. 3(a). It has been found that Urs-GLDH/ZnO-CH/ITO bioelectrode is not significantly affected due to presence of these interferents. And the value of the current remains nearly same except for cholesterol wherein there is a decrease of about $5 \%$.

$\mathrm{ZnO}-\mathrm{CH}$ based nanobiocomposite electrode has been used to immobilize Urs-GLDH to fabricate electrochemical urea biosensor. The Ur-GLDH/ZnO-CH/ITO urea biosensor shows improved characteristics such as linearity as $5-100 \mathrm{mg} / \mathrm{dl}$, low detection limit $(3 \mathrm{mg} / \mathrm{dl})$, linear regression as 0.988 , standard deviation as $9.4 \mu \mathrm{A} / \mathrm{mg} \mathrm{dl}^{-1}$, response time of $10 \mathrm{~s}$, and shelf life of 3 months. The value of Michaelis-Menten constant $\left(K_{m}\right)$ obtained as $4.92 \mathrm{mg} / \mathrm{dl}$ $(0.819 \mathrm{mM})$ indicates high affinity of Urs-GLDH to urea. Efforts should be made to utilize this Urs-GLDH/ZnO-CH/ ITO bioelectrode for estimation of urea in serum samples and utilize it for fabrication of other biosensors.

We thank Director, National Physical Laboratory for providing facilities. P.R.S., A.A.A., and A.K. thank CSIR, India for award of Senior Research Associateships and Senior Research Fellowship.

${ }^{1}$ Rajesh, V. Bisht, W. Takashima, and K. Kaneto, Biomaterials 26, 3683 (2005)

${ }^{2}$ B. Lakard, G. Herlem, S. Lakard, A. Antoniou, and B. Fahys, Biosens. Bioelectron. 19, 1641 (2004).

${ }^{3}$ G. Dhawan, G. Sumana, and B. D. Malhotra, Biochem. Eng. J. (unpublished).

${ }^{4}$ A. Maaref, H. Barhoumi, M. Rammah, C. Martelet, N. Jaffrezic-Renault, C. Mousty, and S. Counier, Sens. Actuators B 123, 671 (2007).

${ }^{5}$ E. J. Sampson, M. A. Baird, C. A. Burtls, E. M. Smith, D. L. Wltte, and D. D. Bayse, Clin. Chem. 26, 816 (1980).

${ }^{6}$ A. A. Ansari, P. R. Solanki, and B. D. Malhotra, Appl. Phys. Lett. 92, 263901 (2008).

${ }^{7}$ H. J. Kim, S. H. Yoon, H. N. Choi, Y. K. Lyu, and W. Y. Lee, Bull. Korean Chem. Soc. 27, 65 (2006).

${ }^{8}$ S. P. Singh, S. K. Arya, P. Pandey, B. D. Malhotra, S. Saha, K. Sreenivas, and V. Gupta, Appl. Phys. Lett. 91, 063901 (2007).

${ }^{9}$ J. X. Wang, X. W. Sun, A. Wei, Y. Lei, X. P. Cai, C. M. Li, and Z. L. Dong, Appl. Phys. Lett. 88, 233106 (2006).

${ }^{10}$ S. Krishnamoorthy, T. Bei, E. Zoumakis, G. P. Chrousos, and A. Iliadis, Biosens. Bioelectron. 22, 707 (2006).

${ }^{11}$ A. Wei, X. W. Sun, J. X. Wang, Y. Lei, X. P. Cai, C. M. Li, Z. L. Dong, and W. Huang, Appl. Phys. Lett. 89, 123902 (2006).

${ }^{12}$ R. Khan, A. Kaushik, P. R. Solanki, A. A. Ansari, M. K. Pandey, and B. D. Malhotra, Anal. Chim. Acta 616, 207 (2008).

${ }^{13}$ J. Cruz, M. Kawasaki, and W. Gorski, Anal. Chem. 72, 680 (2000).

${ }^{14}$ Y. Miao and S. N. Tan, Analyst (Cambridge, U.K.) 125, 1591 (2000).

${ }^{15}$ C. Xu, H. Cai, P. He, and Y. Fang, Analyst (Cambridge, U.K.) 126, 62 (2001).

${ }^{16}$ Y. L. Liu, Y. H. Yang, H. F. Yang, Z. M. Liu, G. L. Shen, and R. Q. Yu, J. Inorg. Biochem. 99, 2046 (2005).

${ }^{17}$ A. Kaushik, J. Kumar, K. K. Tiwari, R. Khan, B. D. Malhotra, V. Gupta, and S. P. Singh, J. Nanosci. Nanotechnol. 8, 1757 (2008). 